\title{
La creatividad publicitaria y su influencia social en la vigorexia masculina
}

Carlos Fanjul Peyró | fanjul@com.uji.es

Cristina González Oñate | onate@com.uji.es

UNIVERSIDAD J AUME I (CASTELLÓN)

Resumen: Las características físicas de los modelos masculinos publicitarios es un aspecto no verbal del mensaje que suele ser utilizado en los procesos creativos de determinados anuncios, para atraer y dotar al producto/marca anunciado de atributos que objetivamente no posee. La vigorexia es una reciente psicopatología que provoca, en quienes la sufren, alteraciones en su percepción somática con cuadros depresivos y obsesivos. Por su influencia y repercusión social, la publicidad de determinados productos y los modelos allí representados, parecen erigirse como uno de los factores del macroentorno social que influye en el origen y desarrollo de esta nueva patología.

Palabras clave: publicidad, vigorexia, comunicación no verbal, creatividad

Abstract: The physical characteristics of advertising models is a nonverbal aspect of the message that be used in the creative processes of determined ads, to attract and give to the product/brand announced attributes that objectively does not possess. Vigorexia is a recent psychopathology that moves, in those who suffer it, alterations in their somatic perception with depressive and obsessive symptoms. Due to its influence and social repercussion, advertising of certain products and models there represented, seem to set up as one of the factors of the social macroscene that influences on the origin and development of this new pathology.

Key words: advertising, vigorexia, nonverbal communication, creativity 


\section{Introducción}

La excesiva preocupación por el aspecto físico, unida a las creencias sobre los beneficios del cuerpo perfecto, provoca nuevas necesidades dirigidas a la consecución de ideales estéticos socialmente establecidos. En ocasiones, éstas se convierten en obsesiones cegadoras que alejan al individuo de su realidad y lo dirigen hacia sendas autodestructivas. La anorexia, la bulimia o, más recientemente, la vigorexia son enfermedades y patologías que se encuentran enmarcadas dentro de este contexto.

La belleza, la apariencia y las características físicas son aspectos del ser humano que se han erigido como estandartes sociales, dentro de la actual era de la imagen. Cada vez se depende más de estímulos visuales para entender y comprender el mundo. El "homo sapiens" ha evolucionado hacia el "homo iconicus", la razón se ha subyugado a la imagen y el hombre se ha escabullido dentro del embelesamiento por ésta y por el placer del estímulo de los sentidos. Todo ello se ha consolidado como los valores dominantes de la vida, unos valores que reducen el mundo a cuestiones materiales, efímeras e inconsistentes (García García, 2003).

La publicidad, en sus distintas formas y presentaciones, es fiel reflejo de estos cambios y nuevos valores. Sus mensajes se han integrado en la sociedad de forma indisoluble y se han convertido en un elemento tan cotidiano como imprescindible. Cotidiano porque ya no se concibe un producto sin marca (aunque se trate de las denominadas "marcas blancas") e imprescindible, tanto para consolidar y desarrollar el mercado (economía) como para mantener, potenciar o modificar actitudes y valores sociales. El discurso publicitario hace uso de todos los componentes de la comunicación para elaborar sus mensajes buscando siempre objetivos de información, persuasión y seducción. Este entramado de la comunicación comercial provoca que los creativos publicitarios estudien, trabajen y construyan los códigos verbales y no verbales del mensaje para conseguir influir y atraer al receptor, tanto en sus propuestas explícitas (denotadas) como implícitas (connotadas). El producto, la marca, los valores, los ideales... todo queda imbricado en una pieza creativa que esconde más de lo que aparentemente muestra.

\section{El proceso creativo y la capacidad de significancia en el discurso publicitario}

En una sociedad como la actual, donde el poder de la imagen está sobrepasando al poder de la palabra y donde, cada vez más, los valores sociales y culturales son transmitidos a través de las imágenes ofrecidas por los medios de comunicación, se hace necesaria una mayor atención y un exhaustivo estudio sobre la capacidad de significancia (entendida como la construcción del sentido) de los textos y mensajes icónicos. Principalmente, son estas cuestiones las que impulsan los estudios semióticos de la imagen, que encontrarán un atractivo filón de investigación dentro del campo publicitario (Sánchez, 1997; Rodríguez y Mora, 2002). 
La significación (entendida como la relación entre un significante y un significado) se produce gracias al proceso de significancia que es definida por Eguizábal y Caro (1996) como el efecto de sentido que se produce por el juego de los significantes dentro de un enunciado. Es cierto que resultaría difícil transmitir o estructurar la realidad si no se contara con unos significantes asociados a unos significados, gracias a lo cual poder expresar pensamientos y comunicar. Pero, el sentido de todo ello se consigue cuando los significantes se unen en una cadena y se entrelazan (efecto recíproco de los significantes o proceso de significancia). "No se trata de realizar una combinación u ordenación mecánica de los elementos, sino de una fusión, de lograr que el conjunto sea superior, diferente a la suma de las partes y que tenga significación." (García García, 2003:17)

La falta de diferenciación, el crecimiento de la competencia, la búsqueda de una personalidad propia de producto y marca, la necesidad de forjarse un hueco en el mercado y en la mente del consumidor provoca que los anunciantes (empresas) soliciten y exijan a su publicidad crear un "objeto semiótico" a expensas de su "objeto económico". Bassat (1993) argumenta que, en esa situación actual de saturación e indiferenciación de productos y mercados, con un consumidor cada vez más exigente e informado, las decisiones de compra se rigen más por cuestiones pasionales que racionales. En los países más desarrollados, el consumo se ha convertido, más que una actividad económica, en un rito simbólico, una actividad social y comunicativa que comporta una carga de significado, una construcción de sentido (Bono, 1992; Echevarría, 1995).

Ante esta situación, la creatividad publicitaria busca encontrar en la elaboración de sus piezas aquellos aspectos que hagan al producto o servicio distinto de la competencia y que, a su vez, personalicen y den notoriedad a la marca. Para conseguirlo, pone el énfasis en otro tipo de beneficios que van más allá del bien anunciado, apoyándose para ello más en la forma que en el contenido del mensaje. La publicidad mediada se va transfigurando así de una publicidad referencial (dirigida de forma más racional sobre el objeto anunciado y sus características) hacia una publicidad relacional (dirigida hacia la parte más emocional vinculando valores, ideales, símbolos... al producto y su consumo).

La semiótica de la narrativa publicitaria ha puesto en evidencia la existencia de estructuras profundas que organizan el discurso creativo, verbal y/o no verbal, comercial. En este contexto, la publicidad se concibe como un mapa de relaciones donde se entrelazan y se complementan signos, registros y códigos provenientes de distintos campos (humano, audiovisual, literario, imaginario...) que, como en una orquesta, confluyen y generan una única pieza final cargada de sentido y significado propio y que no se entendería si se analizasen de forma independiente cada una de sus partes (Bateson, 1994; Péninou, 1976). 


\section{Códigos no verbales de la realidad, del discurso e ideológicos}

Los códigos son el instrumento que hace posible establecer una correspondencia común entre significantes y significados y que permite determinar, comprender y descifrar el proceso de significancia que enlaza los distintos significantes hacia un sentido y valor determinado. La exhaustividad en el estudio de los elementos que constituyen cada uno de esos códigos y su interrelación, garantizará una mayor y mejor comprensión de cuestiones tales como la intencionalidad del mensaje, influencia y repercusión, tanto en lo referente a cuestiones estrictamente comerciales como sociales y culturales.

La publicidad, al tratar de simular o recrear, en la mayoría de sus piezas, situaciones o historias en las que participan personas que interactúan (bien entre sí o bien con el espectador-receptor), plasma y hace uso de la comunicación no verbal humana en la elaboración de sus mensajes. Sin embargo, si se entiende la comunicación no verbal como lenguaje corporal humano exclusivamente, se descartan otros lenguajes no verbales (narrativa audiovisual, tipografía, etc.) para centrarse fundamentalmente en la presencia de personas y su relación con otros objetos, otras personas y con el entorno en los anuncios publicitarios (caracterización, movimientos, contexto físico...).

Para conseguir su significación global, la publicidad se sirve de los códices propios del lenguaje fílmico, dentro de los cuales podemos distinguir entre códigos de la realidad, códigos del discurso y códigos ideológicos (Cassetti y Di Chio, 1999). Los primeros hacen referencia a aquellos que se vinculan directamente con el ser humano y que comprenderían tanto los códigos verbales (discurso de los sujetos en escena) como los no verbales (gestos, expresión facial, apariencia física, posturas, etc.). Por códigos del discurso se entienden todos aquellos elementos propios del lenguaje audiovisual, distinguiendo en ellos cinco tipos: visuales (encuadres, planos, tomas, iluminación, movimientos de cámara), gráficos (títulos, subtítulos, superposiciones, logotipos), sonoros (voces, ruidos, músicas), sintácticos (montaje de las imágenes) y temporales (modalidades de transmisión). Y, finalmente, los ideológicos serían aquellos códigos simbólicos tomados del sistema social y cultural, que engloban y organizan tanto a los códigos de la realidad como del discurso (valores, estilos de vida).

La conjunción de elementos verbales y no verbales de la comunicación humana, de componentes no verbales del discurso y de los factores simbólicos del mensaje, constituirán el lenguaje publicitario y dotarán, en su conjunto, de pleno sentido y significado al anuncio. El estudio del producto y la marca, la personalidad de la empresa anunciante, el análisis del mercado, los objetivos a alcanzar, las características del público, las motivaciones de éstos y un largo etcétera, serán aspectos claves que deberán ser tenidos en cuenta a la hora de dar forma a la pieza creativa publicitaria y que jugarán un papel esencial en aspectos como el contexto en el que se enmarca el anuncio, selección de actores, determinación de voces, elaboración de textos, diseño gráfico, elección de ilustraciones y fotografías, colores... Los creativos, con la conjunción de todos estos elementos, irán forjando el sentido global, la 
interpretación y la significación pretendida del anuncio. La creatividad en la fusión de estos códigos de la realidad, del discurso e ideológicos en una pieza con una concepción global, enriquece y amplia las posibilidades y capacidades comunicativas de los mensajes publicitarios. Todo ello determinará el resultado final creativo e influirá en la eficacia, pertinencia, aceptación y repercusión del anuncio, del producto/marca y de los valores e ideales vinculados al mismo (Rey, 1992; García J iménez, 1993).

Las características del medio por el que se va a emitir la pieza publicitaria también determinarán qué elementos de la comunicación no verbal primarán sobre otros para la elaboración, transmisión y creación de sentido en sus mensajes. En la radio, las características fonoestésicas de la voz (entonación, timbre, velocidad...), junto con la música y los efectos sonoros, adquieren especial relevancia a la hora de crear sus anuncios. Los mensajes publicitarios impresos cuidarán especialmente aspectos propios de la proxémica y kinésica (composición, distribución, posturas, luces, colores, sombras, etc.) quedando relegadas otras áreas de la comunicación no verbal (sobre todo aquellas que se vinculan con el movimiento, ya que en prensa escrita éste desaparece). La publicidad en cine y televisión, al ser de carácter audiovisual, imbrica y utiliza magistralmente, prácticamente, todos los aspectos no verbales de la comunicación humana y del discurso, constituyéndose así en la más rica y completa a la hora de abordar la creación de cualquier pieza publicitaria (Knapp, 1995; Lorenzo, 2000).

\section{Publicidad y repercusión social}

Con este entramado creativo, el mensaje publicitario consigue transmitir a sus receptores algo más que la oferta de un bien; connotativamente ofrece posibilidades, ilusiones, capacidades... en definitiva, una superación de la realidad a través de la ensoñación y la idealización. La marca de un producto no identifica ya al producto, identifica al consumidor como miembro de un grupo de consumidores con una serie de características y valores, con un status y un posicionamiento (González y Ortiz, 1999). El sujeto y el objeto devienen en uno. Incluso hay publicidad que se ha centrado sólo en el valor añadido de la marca, llegando a obviar el producto.

La publicidad, al pasar de "vender productos" a "vender valores" se convierte en un factor tanto económico como social y cultural. En estas últimas décadas, la comunicación publicitaria se ha transformado yendo más allá de su referente. Como discurso, se instaura dentro de la era de los signos en la que domina más la imagen-representación que la realidad-historia. La mediación pasa cada vez más por el discurso, por una economía política del signo en un proceso que está operando una culturización de lo social consistente en hacer de los signos culturales signos de distinción, esto es, de indicadores sociales (Pérez Tornero, 1992). En el capitalismo de consumo, la publicidad ya no es referencial sino estructural: se refiere a sí misma (es una indicación significativa). Se establece así un imperio de las formas que tiene su principal vehículo en la publicidad (como creadora de 
signos de identificación o imagen de marca), no sólo en la vertiente comercial sino también social, política o institucional. "La publicidad ha dejado de ser ya, desde hace mucho tiempo, un simple medio de información sobre las cualidades materiales de los productos de consumo. Estos se presentan en ella como objetos ideales, dotados de propiedades maravillosas, fundamentalmente alejados de lo que la experiencia cotidiana nos enseña" (De Lucas, 1988: 22).

La publicidad, como comunicación comercial, masiva y mediada, se erige en la sociedad actual como estandarte de la nueva ideología del "bienestar". Sus mensajes transmiten la idea de que el consumo es la vía más directa a la felicidad. El materialismo y la búsqueda de placer son los valores en alza; es lo que prima en la nueva sociedad. La publicidad crea moda y la moda se convierte en arte. Los bienes, además de objetos, se convierten en símbolos. Símbolos que representan unos valores, unas aspiraciones, unas formas de pensar y actuar siempre acordes con el orden social establecido (Maciá, 2000).

El contexto en el que la publicidad envuelve sus productos, esos valores, ideales, emociones, esa referencia subjetiva que la publicidad confiere al producto/marca para diferenciarlo y persuadir al consumidor, viene dado, en la mayoría de los casos, en el mensaje connotado, latente, de la publicidad. Y son los componentes de la comunicación no verbal del anuncio los principales creadores y portadores de toda esta significación. Cabe destacar que, entre otras razones, la mayoría de los símbolos que se crean y se consumen hoy tienden a ser de naturaleza no verbal porque los códigos no verbales presentan una mayor facilidad de asimilación y presentan un mayor número de ventajas para universalizarse.

Todo lo percibido por los seres humanos puede considerarse como simbólico, o funcional o como ambas cosas. El significado simbólico funciona dentro del inconsciente ya sea verbalmente o no. Los símbolos implican más bien lo que un objeto o situación significa para nosotros, que lo que nos diría. Los significados simbólicos parecen constituir la base sobre la cual la percepción se convierte en algo profundamente significativo. (Bryan Key, 1991: 106).

Los espacios, los modelos utilizados, los estereotipos, las características del entorno, la conducta de los actores, sus gestos, su aspecto físico y un largo etcétera, son los componentes del mensaje que dotarán de carga simbólica y sentido social al contenido que se ofrece. En este sentido, se podría decir que la comunicación no verbal de la publicidad, puede influir y determinar, en cierto grado, los hábitos y pautas de comportamiento social.

\section{Códigos no verbales de la realidad en los modelos publicitarios y su influencia social en la vigorexia masculina}

La vigorexia se puede definir de forma genérica como una psicopatología somática que se caracteriza, principalmente, por una percepción alterada de la propia constitución física, unida a una sobreestimación de los beneficios psicológicos y sociales de tener un cuerpo musculado. Es una patología que afecta, principalmente, a los hombres y que se manifiesta en actitudes y comportamientos excesivos que van dirigidos hacia el desarrollo muscular. Los 
sujetos vigoréxicos buscan alcanzar el "cuerpo perfecto" a cualquier precio; no dudan en pasar horas y horas entrenando en el gimnasio, sacrifican su alimentación en pos de una comida monótona, baja en grasa y rica en proteínas, y para ellos el consumo de sustancias sintéticas (anabolizantes y esteroides) con el fin de obtener más músculo, no supone ningún problema (Pope, 2001; Fanjul, 2008).

El comportamiento vigoréxico no es provocado por un único motivo, sino que tendremos que hablar siempre de un modelo multicausal; un compendio de varios factores, tanto individuales como sociales, que convergen y se fusionan hasta desencadenar y favorecer el desarrollo de esta patología. En algunos casos primarán las cuestiones psicológicas y personales, y en otros destacarán las cuestiones sociales y estéticas, pero en todos ellos el desenlace implicará el desarrollo de la vigorexia. Sin embargo, bien sea por unas causas u otras, hay que tomar consciencia de que todas ellas se encuentran reforzadas y potenciadas por los valores materialistas que imperan en las sociedades occidentales y que se han consolidado como ideales a alcanzar (Baile, 2005).

La preocupación por el aspecto físico, la autoimagen y la sobrevaloración del cuerpo afecta igualmente a hombres y mujeres; sin embargo, mientras que socialmente a las mujeres se les induce hacia la búsqueda de un cuerpo delgado y estilizado, a los hombres se les conduce hacia el desarrollo muscular y la definición corporal. Los medios de comunicación y la publicidad utilizan códigos no verbales de la realidad, como la belleza, el aspecto y el atractivo físico, para crear mensajes llenos de valores materialistas, narcisistas y hedonistas, configurando y reforzando unos estereotipos ideales de belleza (casi inalcanzables) que responden más a criterios mercantilistas que a modelos de salud y bienestar (Rey, 1994; Mosse, 2001).

El mensaje publicitario masivo también se hace eco del valor actual por el cuerpo y el aspecto físico, utilizándolo como reclamo y como transmisor de connotaciones deseables que se fusionan con el producto o servicio anunciado. Se quiera o no, los componentes no verbales del ser humano comunican e incluso tienen, o pueden tener, más peso y credibilidad que los aspectos verbales del mismo. En una época como la actual, donde prima la omnipresencia mediática, la comunicación y la imagen, se puede observar como la publicidad utiliza, recrea y juega con estereotipos, símbolos e iconos que le facilitan esa vinculación connotativa de valores socialmente deseables al producto o marca que anuncia (Pérez Gauli, 2000).

Los cuerpos magros y musculados de los modelos masculinos que imperan en determinados tipos de anuncios son, además de un reclamo visual, un componente no verbal del mensaje. Éstos transmiten un modelo estético de belleza, al que van ligados de forma connotada valores socialmente deseables tales como el éxito, el poder, el estatus o el sexo. Este aspecto físico promulgado masivamente es interiorizado, elevado y buscado por los hombres, ya sea de forma consciente o inconsciente. Cuanto más alejado esté ese ideal de la propia realidad corporal, más insatisfechos se sienten y piensan que, aproximándose a él, 
conseguirán restablecer la seguridad en sí mismos, obteniendo así éxitos a todos los niveles (Thornton y Ryckman, 1991; Walster, 1996).

El vigoréxico es un hombre que percibe de forma distorsionada la realidad de su propio cuerpo; nunca se ve tal como es, siempre hay aspectos que son mejorables, que no son "perfectos". El hecho de tener un estereotipo socialmente establecido como modelo ideal a alcanzar, favorece ese sentimiento de insatisfacción hacia el propio cuerpo, pudiendo así llegar a desarrollar comportamientos y actitudes obsesivo-compulsivas, dirigidas hacia la consecución de ese ideal a cualquier precio (Castillo, 2004; Castells, 2006).

Para corroborar todas estas cuestiones y determinar la posible relación causal entre el modelo estético difundido por la publicidad y la potenciación y/o desarrollo de la vigorexia, se llevó a cabo una investigación sobre la apariencia y características físicas de los modelos publicitarios masculinos como códigos no verbales de la realidad y como factor de influencia social mediática en la vigorexia.

En busca de la consecución de resultados significativos sobre el tema de la vigorexia, el primer paso necesario era concretar el perfil de las personas que serían sujetos de estudio. El criterio básico a la hora de seleccionar la muestra fue que los encuestados fueran usuarios de la sala de musculación de un gimnasio, ya que es precisamente en estos recintos donde se podría encontrar más fácilmente a hombres con tendencias vigoréxicas o vigoréxicos. Para llevar a cabo la investigación, se confeccionó una encuesta que abordaba temas tales como apariencia física, valores sociales, obsesión por el desarrollo muscular, modelo masculino predominante en la publicidad, grado de influencia percibida por la publicidad, etc. Esta encuesta estaba compuesta por un total de 30 cuestiones (la mayor parte de ellas cerradas, con una respuesta en escala de 5 grados) que buscaban obtener información relevante de los tres ámbitos que pueden influir en el desarrollo y/o potenciación de la patología vigoréxica: individual, microentorno y macroentorno.

El estudio se llevó a cabo en 5 gimnasios de Valencia capital y las encuestas fueron cumplimentadas por un total de 195 usuarios de salas de musculación. Esta actividad se realizó en horario vespertino (de 18.00h. a 22.00h.) debido a que, en esta franja horaria, es cuando más clientes hay en los gimnasios, esencialmente gente joven que son el principal sector de riesgo para caer y desarrollar cuadros vigoréxicos. Una vez en posesión de las encuestas cumplimentadas, se procedió a extraer una muestra de sujetos potencialmente vigoréxicos tomando como variable más significativa sobre esta cuestión la necesidad/prioridad que habían manifestado los encuestados en conseguir una mayor masa muscular. El objetivo de esta segunda muestra era poder comparar las respuestas de estos hombres con las aportadas por el resto. Con esta determinación, se obtuvieron un total de 39 sujetos potencialmente vigoréxicos.

Tras el análisis de ambas muestras, se extrajeron resultados muy significativos sobre el objeto de estudio que interesaba analizar. Respecto a la edad de los encuestados, un 
representativo $80 \%$ se encontraba entre los 15 y los 30 años. Por tanto, se trataría de una muestra de sujetos eminentemente jóvenes que, como ya se ha referido anteriormente, englobaría al principal grupo de riesgo a la hora de desarrollar la psicopatología vigoréxica.

En el ámbito individual, respecto a la valoración que hacen los sujetos de estudio de la apariencia y características físicas como factores que influyen en cuestiones personales y sociales, se puede establecer, a la vista de los resultados, una vinculación positiva entre estos elementos. La mayor parte de los encuestados considera que el aspecto físico de una persona influye muy significativamente en la autoestima que ésta tenga, así como en el éxito a todos los niveles (personal, social, laboral) y en la aceptación social.

\begin{tabular}{|l|c|c|}
\hline & USUARI OS GI MNASIO & $\begin{array}{c}\text { POTENCI ALES } \\
\text { VI GORÉXI COS }\end{array}$ \\
\hline \hline AUTOESTI MA & $74.4 \%$ & $89.7 \%$ \\
\hline ÉXITO & $66.2 \%$ & $84.6 \%$ \\
\hline ACEPTACIÓN SOCI AL & $47 \%$ & $66.7 \%$ \\
\hline
\end{tabular}

\section{Tabla 1. I nfluencia de las características físicas en la autoestima, el éxito y la aceptación social}

El nivel de influencia percibido por el grupo de potenciales vigoréxicos es sensiblemente mayor respecto a los niveles manifestados por el grupo de usuarios de gimnasio, lo cual viene a manifestar que la vinculación de valores socialmente positivos a aspectos estrictamente somáticos está mucho más acentuada en este grupo.

Respecto a la percepción corporal destacan dos cuestiones. A los encuestados se les ofrecía la siguiente escala somática creciente del 1 al 10:

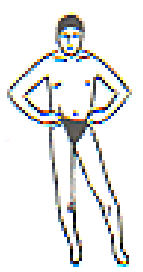

1

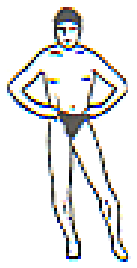

2

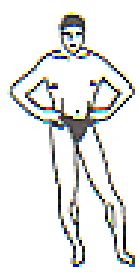

3

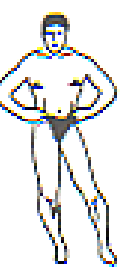

4

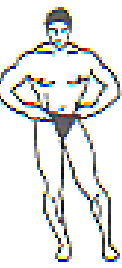

5

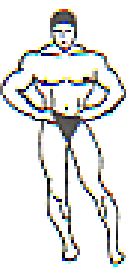

6.

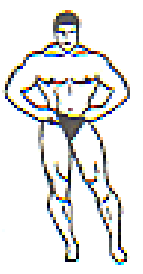

7

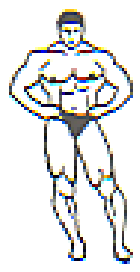

B

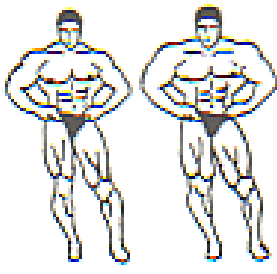

10

* Fuente: Baile, J. (2005), Vigorexia. Cómo reconocerla y evitarla. Madrid: Síntesis, p. 89.

Laprimera cuestión les pedía que escogieran qué somatipo se correspondería, según su criterio, a un cuerpo sano y saludable y cuál sería el ideal que les gustaría alcanzar. En la muestra de usuarios de gimnasio, alrededor del 75\% situó estos somatipos entre el número 5 y el 8 (por tanto, lo conciben como un cuerpo con un desarrollo muscular notable). Por su 
parte, la misma cuestión evaluada por la muestra de potenciales vigoréxicos varía sustancialmente en esta percepción. Para un $80 \%$ de ellos, el cuerpo que consideran como sano y saludable y como ideal a alcanzar, se ubica entre los somatipos 7 y 10 (con un desarrollo muscular propio de sujetos vigoréxicos). Por tanto, se comprueba que este grupo tiene una distorsión mayor que la media sobre la concepción de un cuerpo en forma; para ellos, cuanto mayor sea el desarrollo y la definición muscular, más se aproximan al ideal somático que tienen mentalmente como referente al que hay que aspirar. En ambos grupos parece confirmarse la idea de que los hombres valoran un cuerpo masculino como "en forma" en función del desarrollo y la definición muscular que presente, decantándose, mayoritariamente, por modelos que no lleguen a rozar los límites del exceso muscular.

La siguiente cuestión solicitaba de los encuestados que, sobre la misma escala somática, evaluaran la percepción que ellos tenían sobre su propio cuerpo. Los usuarios de gimnasio se situaron mayoritariamente ( $75 \%$ ) entre los somatipos del 3 al 6 , mientras que la muestra de potenciales vigoréxicos se situó en un $63 \%$ de los casos entre el 1 y el 4 . Por tanto, a la hora de valorar su propia constitución física, se confirma que, en ambos casos, la percepción entre su realidad física y la idealizada difieren notablemente, y de forma extrapolar en el caso de los potencialmente vigoréxicos.

Comparando estas cuestiones se comprueba como prácticamente en un $70 \%$ de los casos de ambas muestras, la distorsión entre su realidad corporal y el ideal somático está muy acentuada, lo que viene a corroborar que el principal motivo que puede originar y desarrollar la vigorexia está presente en la mayor parte de los hombres que acuden asiduamente al gimnasio.

Para finalizar el análisis del ámbito individual estudiado en las encuestas, resulta interesante recapitular los datos obtenidos sobre un aspecto esencial, en la determinación de cierto grado obsesivo, respecto a la necesidad del desarrollo muscular: el consumo indiscriminado de esteroides y anabolizantes (componentes sintéticos destinados a hacer crecer y definir el músculo en un tiempo récord, acompañado de estrictas dietas y frecuente entrenamiento). El $40 \%$ de los usuarios de gimnasio y casi el $80 \%$ del grupo de potencialmente vigoréxicos, confesó consumir drogas o estar planteándose la posibilidad de hacerlo, con el fin de aumentar su tamaño muscular. Porcentajes muy significativos y que vendrían a reflejar que el problema emergente del consumo de esteroides anabolizantes (y la consecuente evolución del mercado negro de este tipo de productos) comienza a no ser una cuestión que atañe sólo a individuos con patologías graves o moderadas de dismorfia muscular, sino a cualquier sujeto que por motivos estéticos se obsesione con obtener un cuerpo definido y musculado en pos de alcanzar un ideal somático socialmente establecido y reconocido.

Los datos conseguidos en relación a la influencia del microentorno respecto a la obsesión por el culto al cuerpo y la apariencia física propia de los sujetos vigoréxicos, reflejan el hecho de que, aunque sí que existe un cierto grado de influencia de la valoración de la familia y amigos sobre el aspecto físico, el nivel de presión que ejercen éstos resulta menor que el 
desarrollado por los medios de comunicación y, especialmente, la publicidad (factores del macroentorno).

A este respecto, cabe destacar los siguientes resultados obtenidos en esta área y que arrojan luz a la cuestión que se debate en este artículo acerca de la apariencia y las características físicas (códigos no verbales de la realidad) de los modelos publicitarios como factor de influencia social mediática en el desarrollo y/o potenciación de la vigorexia masculina.

Para prácticamente el $80 \%$ de los encuestados en ambas muestras, el modelo estético masculino considerado como más predominante en publicidad es el modelo fitness, que se caracterizaría por ser joven, mesomorfo, atlético, con el torso en forma de " $\mathrm{V}$ ", pecho desarrollado, abdominales marcados o lisos, músculos de piernas y brazos definidos y marcados pero no exagerados, sano y sin grasa. La relevancia de este dato estriba en el hecho de que, aunque estadísticamente sea posible que la publicidad utilice otros modelos que no respondan a estas características, la mayoría de los receptores de la comunicación publicitaria considera a este modelo como predominante. Por tanto, la percepción generalizada de modelo masculino en publicidad respondería a estas características en el posicionamiento mental de los consumidores. Este prototipo responde a su vez al estereotipo social idealizado y asentado en la sociedad actual para el hombre.

Una vez definido este modelo, se les preguntaba sobre la influencia de las características físicas de este estereotipo publicitario en su percepción y valoración corporal, así como si consideraban ese modelo como ideal estético a alcanzar. Con ello se pretendía comprobar si existía una relación entre la interiorización del modelo idealizado y la distorsión somática que había quedado manifiesta en las cuestiones de estudio relacionadas con el ámbito individual. Inmediatamente se observó que sí que se establecía una correlación significativa entre ambos aspectos.

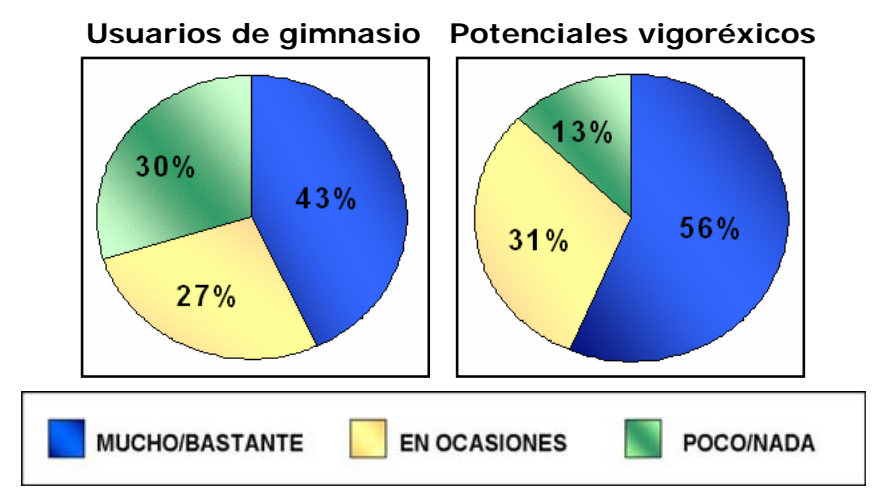

\section{Gráfico I. Influencia de los modelos publicitarios en la autopercepción corporal}


Usuarios de gimnasio Potenciales vigoréxicos

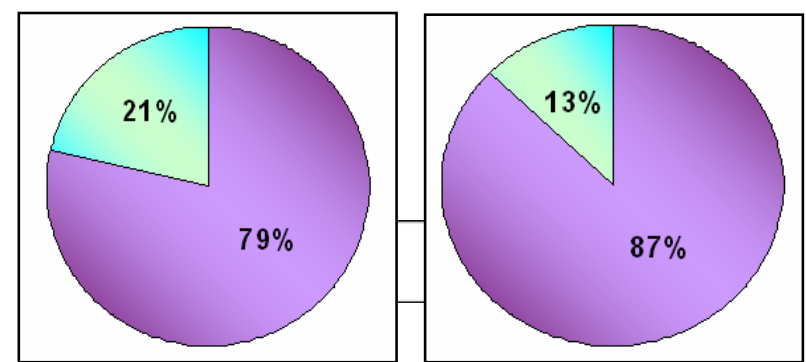

\section{Gráfico II . Los modelos publicitarios como ideal estético a seguir y alcanzar}

Como se puede observar en los gráficos, el $70 \%$ de usuarios de gimnasio y el $87 \%$ del grupo de potenciales vigoréxicos considera que el aspecto físico de los modelos masculinos que aparecen en los anuncios influye significativa y negativamente en la valoración de su propia realidad somática. Además, ambos grupos consideran mayoritariamente a los modelos publicitarios como un ideal estético a seguir y alcanzar, con porcentajes que rondan o superan el $80 \%$. La comparación del propio cuerpo con los modelos idealizados transmitidos por la publicidad se perfila aquí como una de las principales cuestiones que puede motivar la aparición y desarrollo de la psicopatología vigoréxica. Se podría pues considerar que la apariencia y el aspecto físico (códigos no verbales de la realidad), utilizados en determinadas piezas creativas publicitarias, pueden influir de forma significativa en la insatisfacción y frustración con el propio cuerpo (caldo de cultivo de la vigorexia), no pudiendo afirmar categóricamente en ningún caso que esto pueda constituirse como causa única y determinante del desarrollo de la patología, ya que, como se ha comentado anteriormente, ésta respondería a un modelo multicausal.

\section{Conclusiones}

Teniendo en cuenta todo lo referido anteriormente, y a la vista de los resultados más significativos sobre la investigación llevada a cabo y reflejados en este artículo, se podrían extraer las siguientes conclusiones:

1. Estudiando el componente no verbal de la comunicación publicitaria, su utilización, funciones, intenciones e interpretaciones, se puede llegar a estimar su capacidad comunicativa y la influencia de ésta en el proceso de significancia final del mensaje.

2. La creatividad publicitaria hace uso de códigos no verbales de la realidad tales como la belleza, el aspecto y el atractivo físico, para configurar y transmitir, connotativamente, valores, principios e ilusiones que influyen, en mayor o menor medida, en las actitudes y comportamientos de los consumidores. 
3. El "éxito a todos los niveles" es un valor que se vincula directamente con la percepción corporal, lo que influye significativamente en la autoestima y en la preocupación por alcanzar los estereotipos somáticos socialmente establecidos.

4. El estereotipo masculino que se propugna en la actual sociedad de culto al cuerpo, ejerce en el hombre una presión social hacia el ejercicio físico anaeróbico que propicie una imagen de fuerza y potencia (desarrollo muscular).

5. La figura masculina en la publicidad actual, presenta formas estereotipadas que son utilizadas por ésta para elaborar y construir sus mensajes. El hombre considerado como predominante en la publicidad, responde al denominado modelo fitness (un hombre joven, mesomorfo, atlético, con músculos definidos y sin grasa, o con poca).

6. La percepción de un cuerpo masculino en forma, sano y saludable se corresponde con somatipos que presentan una definición muscular similar a la del modelo predominante en publicidad (modelo fitness).

7. La vigorexia es una psicopatología somática que se caracteriza, principalmente, por una percepción alterada de la propia constitución física y una sobreestimación de los beneficios psicológicos y sociales de tener un cuerpo musculado.

8. La presión socio-cultural sobre el cuerpo masculino, trasmitido y potenciado por la publicidad y los media, están influyendo y educando a la población en los beneficios de la imagen y el cuerpo perfecto, estableciendo así a la publicidad como un factor predisponente y mantenedor de la patología vigoréxica.

\section{REFERENCI AS BI BLI OGRÁFI CAS}

BAILE, J. J . (2005): Vigorexia. Cómo reconocerla y evitarla. Madrid, Síntesis.

BASSAT, L. (1993): El libro rojo de la publicidad. Barcelona, Folio.

BATESON, G. [Et. al.] (1994): La nueva comunicación. Barcelona, Kairós.

Bono, E. (1992): El pensamiento creativo. Barcelona, Paidós Empresa.

BRYAN KEY, W. (1991): Seducción Subliminal. Argentina, Vergara/Diana.

CASSETTI, F. y Dı CHIO, F. (1999): Análisis de la televisión. Instrumentos, métodos y prácticas de investigación. Barcelona, Paidós.

CAStells, M. (2006): "Vigorexia: obsesión por un cuerpo musculoso". Disponible en Internet (12.09.08): www.farmaceutoconline.com/cast/familia/familia_vigorexia_c.html

CAStillo, M. (2004): “Vigorexia: mentes enfermas en cuerpos sanos”. Disponible en Internet (12.09.08): www.ondasalud.com/edicion/noticia/0,2458,4825,00.html

De LuCAS, A. (1988): “Publicidad e Ideología" en ALTARES, P. [et. al.]: Anunciar, o la utilidad de la belleza. Madrid, Cuadernos Contrapunto.

EchevarríA, M. A. (1995): Creatividad \& Comunicación. Barcelona, GTE. 
EguizÁBAL, R. y CARO, A. (1996): Medición, investigación e información de la publicidad. Madrid, Comunicación 2000.

FANJ UL, C. (2008), Vigorexia: una mirada desde la publicidad. Madrid: Fragua.

García GarcíA, F. (2003): “Homo iconicus” en I cono 14, 1: 6-15.

García GarcíA, F. (2003): “Posibilidades creativas de la imagen" en Icono 14, 2: 925.

GARCíA J I MÉNEZ, J . (1993): Narrativa audiovisual. Madrid, Cátedra.

González RequenA, J. y Ortiz, A. (1999): El spot publicitario. La metamorfosis del deseo. Madrid, Cátedra.

Knapp, M. L. (1995): La comunicación no verbal. El cuerpo y el entorno. Barcelona, Paidós.

LoRenzo García, J. (2000): Comunicación no verbal. Periodismo y medios audiovisuales. Madrid, Universitas.

Maciá Mercadé, J. (2000): Comunicación persuasiva para la sociedad de la información. Madrid, Universitas.

MosSE, G. L. (2001): La imagen del hombre. La creación de la moderna masculinidad. Madrid, Talasa.

PÉnINOU, G. (1976): Semiótica de la publicidad. Barcelona, Gustavo Gili.

Pérez Gaulı, J. C. (2000): El cuerpo en venta. Madrid, Cátedra.

Pérez Tornero, J. M. [et. al.] (1992): La seducción de la opulencia: publicidad, moda y consumo. Barcelona, Paidós.

PoPE, H. G. [et. al.](2001): The Adonis Complex. The Secret Crisis of Male Body Obssession. USA: Bargain Books.

REY, J. (1992): La significación publicitaria. Sevilla: Alfar.

REY, J. (1994): El hombre fingido. La representación de la masculinidad en el discurso publicitario. Madrid, Fundamentos.

ROdRígueZ, R. y MORA, K. (2002): Frankenstein y el cirujano plástico: una guía multimedia de semiótica de la publicidad. Alicante, Universidad de Alicante.

SÁnCHEZ CORRAL, L. (1997): Semiótica de la publicidad: narración y discurso. Madrid, Síntesis.

THORNTON, B. Y RYCKMAN, R. (1991): “Relationship between physical attractiveness, physical effectiveness and self-esteem: A cross-sectional análisis among adolescence" en Journal of Adolescent, 14(1): 85-98.

WALSTER, E. [et. al.] (1966): "Importance of Physical Attractiveness in Dating Behavior" en Journal of Personality and Social Psychology, 4: 508-516.

[Recibido: 23-07-2009. Aceptado con indicación de correcciones: 15-10-2009. Recepción del artículo corregido: 17-10-2009] 